\title{
THE KINETICS OF SILVER IODIDE FILM FORMATION ON THE SILVER ANODE
}

\author{
VIOLA I. BIRSS \\ Chemistry Department, University of Ottawa, Ottawa, Ontario, Canada \\ and \\ GRAHAM A. WRIGHT \\ Chemistry Department, University of Auckland, Auckland, New Zealand
}

(Received 18 January 1982)

\begin{abstract}
The potentiodynamic formation of $\mathrm{AgI}$ films by reaction (1) on an $\mathrm{Ag}$ rotating disc electrode was studied and the results were compared to previous work regarding the formation of anodic $\mathrm{AgBr}$ and $\mathrm{Ag}_{2} \mathrm{~S}$ films,

$$
\mathrm{Ag}+\mathrm{I}^{-} \rightleftharpoons \mathrm{AgI}+e^{-}
$$

In dilute iodide solutions, a very porous $\mathrm{AgI}$ film is formed at a rate controlled by the diffusion of $\mathrm{I}^{-}$to the electrode surface. At higher iodide concentrations, and particularly in high conductivity supporting electrolytes, a porous AgI film forms at a rate initially limited by ionic migration in solution followed by diffusion of $\mathrm{I}^{-}$in the pores of the AgI film.

In $1 \mathrm{M} \mathrm{NaI}$ solutions, when $\mathrm{AgI}$ becomes rather soluble, thick granular $\mathrm{AgI}$ films form at a rate limited by the solid-state migration of ions in the bulk of the film. On the basis of the low-field model of film growth, the ionic conductivity of these AgI films has been determined to be $8.7 \times 10^{-5} \mathrm{Scm}^{-1}$
\end{abstract}

\section{INTRODUCTION}

A study of the potentiodynamic formation and reduction of an $\mathrm{AgI}$ film on an $\mathrm{Ag}$ substrate in aqueous iodide solutions [reaction (1)] was undertaken in order to compare these results with those obtained from a study of the anodic formation of $\mathrm{AgBr}$ films[1],

$$
\mathrm{Ag}+\mathrm{I}_{(\mathrm{aq})}^{-} \rightleftharpoons \mathrm{AgI}_{(\text {film) }}+e^{-} \text {. }
$$

$\operatorname{In}[1]$, it was found that the reaction between the silver electrode and bromide ions was fast and that physical processes such as ionic diffusion and migration limited the rate of $\mathrm{AgBr}$ film growth. It was also shown in [1] by Scanning Electron Microscopy (SEM) that potentiodynamically formed $\mathrm{AgBr}$ films remained porous throughout their growth, even for film thicknesses up to about $20 \mu \mathrm{m}$.

It is the purpose of this paper to correlate the observed $E / I$ curves and the AgI film morphology, as seen by SEM, with a model of anodic AgI film formation and to compare this model with that obtained for $\mathrm{AgBr}[1]$ and $\mathrm{Ag}_{2} \mathrm{~S}[2,3]$ film formation under similar experimental conditions.

\section{EXPERIMENTAL}

The basic experimental details have been described previously[1]. As before, an Ag rotating disc electrode (rde) was utilized, with a rotation rate of $\omega$, and a roughness factor, $\gamma$, obtained by double layer capacitance measurements[4]. Initially, $\gamma$ was found to be between 2 and 4 but could reach 100 or more with repeated cycles of $\mathrm{AgI}$ film formation and reduction. Because of this large range in $\gamma$, current densities are reported with respect to the apparent electrode surface area in this paper.

\section{RESULTS AND DISCUSSION}

\section{(i) AgI film formation in dilute iodide solutions}

A typical $E / I$ curve for AgI film formation and reduction in dilute iodide solutions is shown in Fig. 1 for a solution of $2.5 \mathrm{mM} \mathrm{NaI}+0.1 \mathrm{M} \mathrm{NaClO}_{4}$. As in dilute bromide solutions [1], the anodic current occurs as a current plateau with a magnitude which is independent of the potential sweep rate, $s$, but which varies linearly with $\omega^{1 / 2}$ and with the iodide concen-

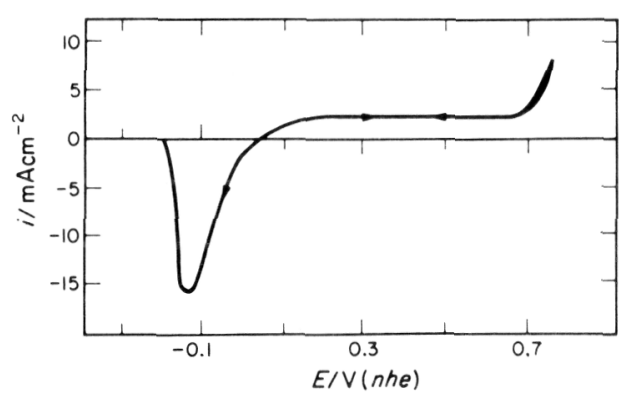

Fig. 1. $E / I$ curve of $\mathrm{Ag}$ in $2.5 \mathrm{mM} \mathrm{NaI}+0.1 \mathrm{M} \mathrm{NaClO}_{4}$ at $s$ $=50 \mathrm{mV} \mathrm{s}^{-1}$ and $\omega=10 \mathrm{~Hz}$. Anodic current plateau reflects rate limitation by the diffusion of iodide ion to $\mathrm{Ag}$ electrode. 
tration, $C$, as is expressed by the Levich equation (2) for a diffusion limited reaction[5].

$$
I=0.62 z F A D^{2 / 3} C v^{-1 / 6} \omega^{1 / 2},
$$

where $z$ is the number of electrons involved in reaction $(1)(=1), F$ is the Faraday constant, $D$ is the diffusion coefficient of $\mathrm{I}^{-}\left(2.1 \times 10^{-5} \mathrm{~cm}^{2} \mathrm{~s}^{-1}[6]\right)$ and $v$ is the kinematic viscosity of the solution $(8.9$ $\left.\times 10^{-3} \mathrm{~cm}^{2} \mathrm{~s}^{-1}[7]\right)$.

The theoretical $I / \omega^{1 / 2}$ relationship of (2) and the experimentally obtained points in several dilute iodide solutions are shown in Fig. 2. The proximity of these two plots indicates that the reaction between $\mathrm{Ag}$ and $\mathrm{I}^{-}$is diffusion controlled under these conditions.

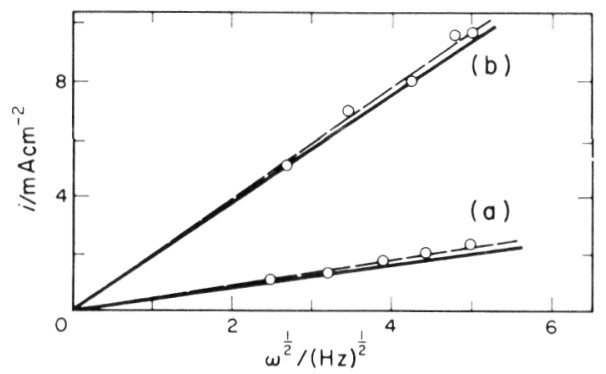

Fig. 2. Experimental $\left(\begin{array}{lll}\theta & 0 & \theta\end{array}\right)$ and theoretical $(\longrightarrow-)(2)$ relationship between plateau current density and $\omega^{1 / 2}$ for $\mathrm{AgI}$ formation in (a) $2.5 \mathrm{mM} \mathrm{I}^{-}$and (b) $11 \mathrm{mM} \mathrm{I}^{-}$solutions at s $=50 \mathrm{mV} \mathrm{s}^{-1}$.

At a potential of about $0.7 \mathrm{~V} /$ nhe in Fig. 1, the anodic current can be seen to increase but without a cathodic counterpart to this current. As in dilute bromide solutions[1], this current has been attributed to the dissolution of $\mathrm{Ag}$ by reaction (3), which implies that the Ag surface is not fully covered by $\mathrm{AgI}$ film under these conditions,

$$
\mathrm{Ag} \rightleftharpoons \mathrm{Ag}^{+}+e^{-} \text {. }
$$

The reduction of the AgI film is seen to occur in a single sharp peak (Fig. 1). In these dilute iodide solutions, the charge consumed in the anodic and in the cathodic sweeps are approximately equal, consistent with the low solubility of AgI at these iodide concentrations.

(ii) AgI film formation in solutions of higher iodide concentration

With an increase in the iodide concentration, $E / I$ curves such as in Fig. 3 are obtained. For a $92 \mathrm{mM} \mathrm{NaI}$ $+83 \mathrm{mM} \mathrm{NaClO}_{4}$ solution, an anodic current peak which no longer depends on $\omega$ but rather depends linearly on $s^{1 / 2}$ is now observed. Therefore, the diffusion of iodide ions to the electrode surface is no longer limiting the rate of $\mathrm{AgI}$ film formation.

At these higher iodide concentrations, comparable to the case of $\mathrm{AgBr}$ film formation[1], the $E / I$ curves of Fig. 3 now display a linear leading edge to the anodic current peak, with an inverse slope $(\sim 130 \Omega)$ which is approximately equal to the calculated ohmic resistance of the solution, $R_{\mathrm{s}}(4)$, between the Ag electrode and the tip of the Luggin capillary leading to the reference electrode[8].

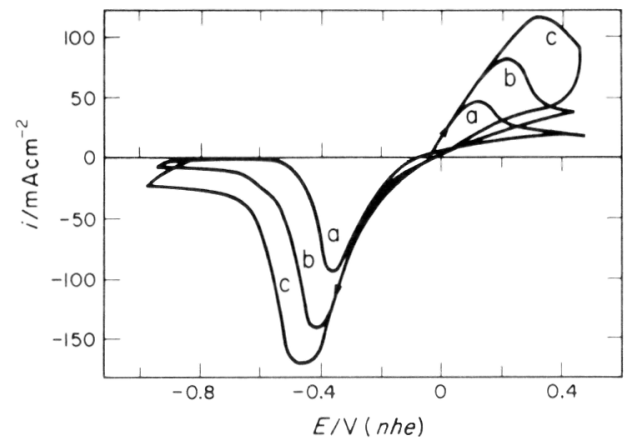

Fig. 3. $E / I$ curves of $\mathrm{Ag}$ in $92 \mathrm{mM} \mathrm{NaI}+83 \mathrm{mM} \mathrm{NaClO}_{4}$ at $\omega=10 \mathrm{~Hz}$ and $s=$ (a) 10 , (b) 30 and (c) $100 \mathrm{mV} \mathrm{s}^{-1}$.

$$
R_{\mathrm{s}}=\frac{1}{2 \pi \kappa a} \tan ^{-1}\left(\frac{z}{a}\right)
$$

where $z$ is the perpendicular distance between the Luggin capillary and the Ag electrode surface, $a$ is the electrode radius and $\kappa$ is the ionic conductivity of the solution. This indicates that in the region of the $E / I$ curves leading to the anodic peak, the migration of ions in solution is now limiting the rate of $\mathrm{AgI}$ film growth. This once again implies that reaction (1) is very fast and that the product, the AgI film, does not behave as an obstructing layer.

(iii) AgI film formation in high conductivity $0.1 \mathrm{M}$ iodide solutions

In order to overcome the ionic migration rate limitation, the growth of $\mathrm{AgI}$ films was then studied in the high conductivity solution of $0.1 \mathrm{M} \mathrm{NaI}$ $+5 \mathrm{M} \mathrm{NaClO}_{4}$. The iodide concentration was not increased to $1 \mathrm{M}$ because $\mathrm{AgI}$ becomes too soluble at higher iodide concentrations.

Figure 4 shows some typical $E / I$ curves at various $s$ for $\mathrm{Ag}$ in this high conductivity solution. It can be seen

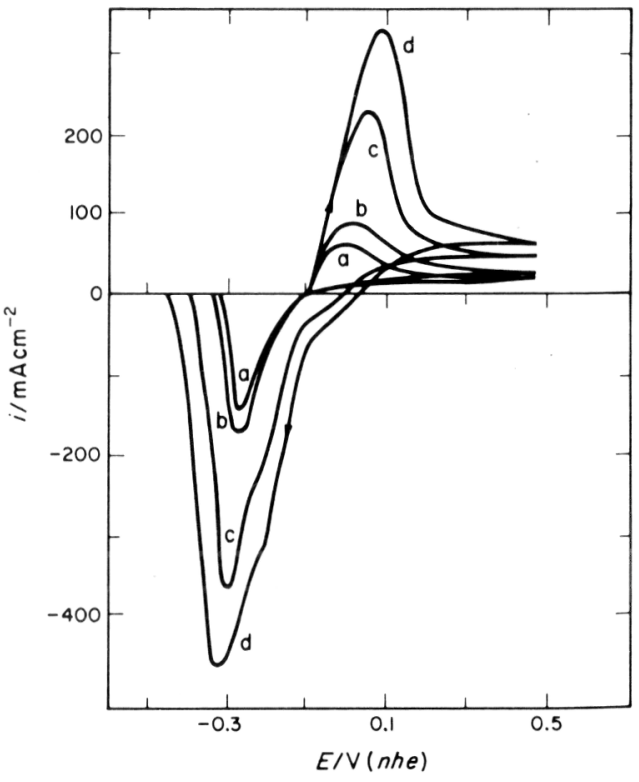

Fig. 4. $E_{/} / I$ curve of $\mathrm{Ag}$ in high conductivity iodide solution $\left(0.1 \mathrm{M} \mathrm{NaI}+5 \mathrm{M} \mathrm{NaClO}_{4}\right)$ at $\omega=18 \mathrm{~Hz}$ and $s=$ (a) 30 , (b) 50 , (c) 150 and (d) $300 \mathrm{mV} \mathrm{s}^{-1}$ 
that the current increases linearly from the formation potential to the peak with an inverse slope of $20 \pm 2 \Omega$. This is once again very similar to the calculated solution resistance, $R_{\mathrm{s}},[=20 \Omega$ by equation (4)] which indicates that ionic migration in solution is still rate limiting.

At the anodic peak, the peak current density is independent of $\omega$ but varies linearly with $s^{1 / 2}$ (Fig. 5). After the anodic peak in Fig. 4, the current decreases gradually with increasing potential, although at a potential of about $0.75 \mathrm{~V}$, evidence of reaction (3) can still be observed. This supports the contention that the Ag surface is still not totally covered with AgI film and that the AgI film is probably porous in nature. This has been substantiated by an SEM examination of such a film surface (Fig. 6) which clearly shows a very porous and granular type of film.

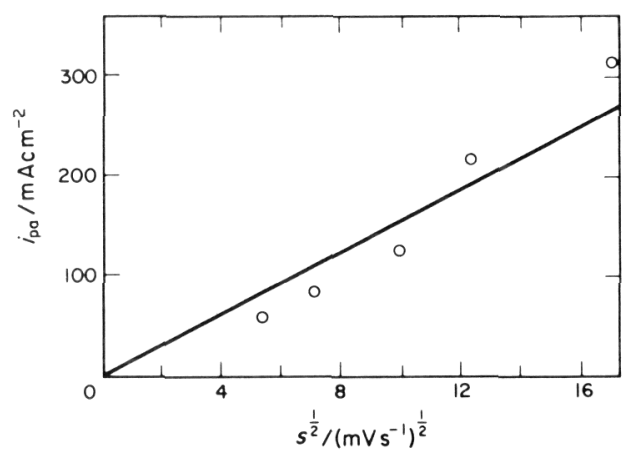

Fig. 5. Experimental $i_{\mathfrak{p}} / s^{1 / 2}$ relationship for AgI film formation under conditions of Fig. 4 at $\omega=18 \mathrm{~Hz}$.

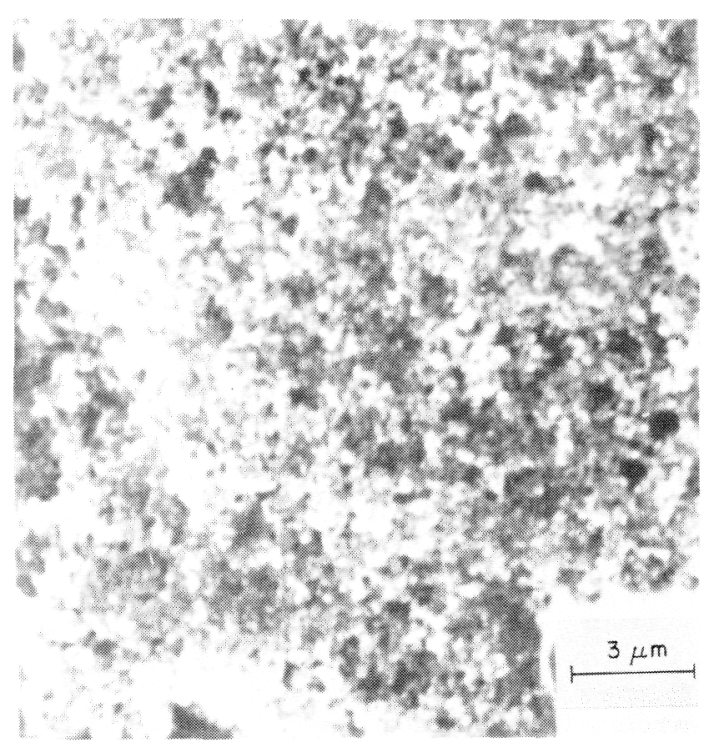

Fig. 6. SEM view of AgI film formed in $0.1 \mathrm{M} \mathrm{NaI}$ $+5 \mathrm{M} \mathrm{NaClO}_{4}$ at $s=100 \mathrm{mV} \mathrm{s}^{-1}, \omega=18 \mathrm{~Hz}$, where the sweep was terminated at about $0.4 \mathrm{~V} /$ nhe (see Fig. 4).

These results in high conductivity iodide solutions bear a strong resemblance to those for the anodic formation of $\mathrm{AgBr}$ films in high conductivity $1 \mathrm{M}$ bromide solutions[1]. This is seen by the control of the current in the anodic peak region of the curves (Fig. 4) by the solution resistance, by the observed linear $i_{\mathrm{p}} / s^{1 / 2}$ relationship, by the gradual decrease of the current after the anodic peak independent of the magnitude of the potential and by the observed film porosity.

In the case of $\mathrm{AgBr}$ film formation[1], all of these observations were linked and the experimentally observed anodic $E / I$ curves were quantitatively simulated by computer on the basis of the following mechanism [9]. AgBr film initiation was considered to occur by the nucleation of small islands of film to a critical nucleus height, which then spread and thicken until only small spaces, or pores, remain between them. Because the electron transfer reaction between $\mathrm{Ag}$ and bromide ion was observed to be fast, this growth regime in high conductivity bromide solutions was considered to be controlled by the resistance of the bulk of the solution and by the resistance of the electrolyte in the pores of the film[10]. When the resistance of the pores becomes large enough, the current peak develops, and a linear $i_{\mathrm{p}} / s^{1 / 2}$ relationship is then theoretically anticipated.

After the current peak, the concentration of the bromide ion was found to become equal to zero at the pore base and then further film thickening was found to be controlled by the diffusion of bromide ions within the pores of the film.

In accordance with this overall model of film growth, AgI film formation in high conductivity $0.1 \mathrm{M}$ iodide solutions is also characterized by a solution resistance controlled current in the region of the anodic peak of the $E / I$ curves (Fig. 4), a linear $i_{\mathrm{p}} / s^{1 / 2}$ relationship (Fig. 5) and a porous AgI film morphology (Fig. 6). However, the observed E/I curves for AgI film growth have not been simulated to date for a final verification of this model of film growth. Nevertheless, it appears that enough similarities exist between the observed electrochemical relationships, the film morphologies and the basic characteristics of $\mathrm{AgBr}$ and $\mathrm{AgI}$ that the same pore resistance and pore diffusion models apply to both $\mathrm{AgI}$ and $\mathrm{AgBr}$ film formation under potentiodynamic conditions in high conductivity solutions.

\section{(iv) AgI film formation in $1.0 \mathrm{M}$ iodide solutions}

In $1.0 \mathrm{M}$ iodide solutions, the solubility of $\mathrm{AgI}$ rises sharply to about $10^{-2} \mathrm{M}[11]$ from a solubility of about $10^{-5} \mathrm{M}$ in $0.1 \mathrm{M}$ iodide solutions. Therefore, the dissolution of $\mathrm{AgI}$ as soluble $\mathrm{AgI}_{n}^{-(n-1)}$ species would be an anticipated feature of the mechanism of AgI film formation in $1.0 \mathrm{M}$ iodide solutions.

Figure 7 shows a typical $E / I$ curve for $\mathrm{Ag}$ in $1 \mathrm{M} \mathrm{NaI}$ solution at $s=50 \mathrm{mV} \mathrm{s}^{-1}$. As in $0.1 \mathrm{M}$ iodide solutions, the anodic current densities are all independent of $\omega$ but vary linearly with $s^{1 / 2}$ (Fig. 8). The inverse of the leading slope to the anodic peak once again depends on the solution conductivity, which indicates that AgI film growth is limited by the ohmic resistance of the solution in this region of the curve (4). However, the $E / I$ curve of Fig. 7 is noticeably different from all of the previous $\mathrm{AgI}$ and $\operatorname{AgBr}[1] E / I$ curves at high halide concentrations, and is instead somewhat reminiscent of the $E / I$ curves for $\mathrm{Ag}_{2} \mathrm{~S}$ film formation[2]. Contrary to the curves of Figs 1, 3 and 4 in 


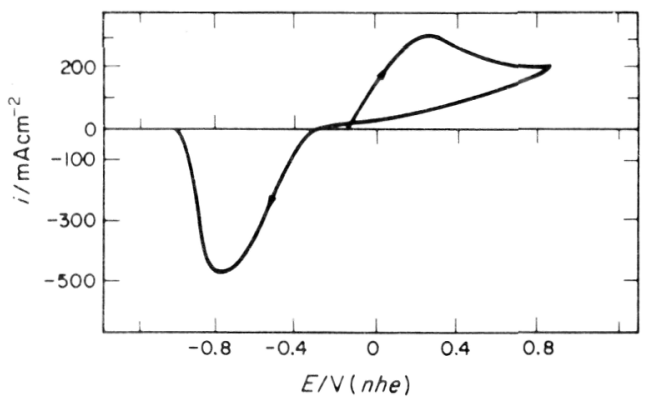

Fig. 7. $E / I$ curve for $\mathrm{Ag}$ in $1 \mathrm{M} \mathrm{NaI}$ solution at $s$ $=50 \mathrm{mV} \mathrm{s}^{-1}, \omega=17 \mathrm{~Hz}$.

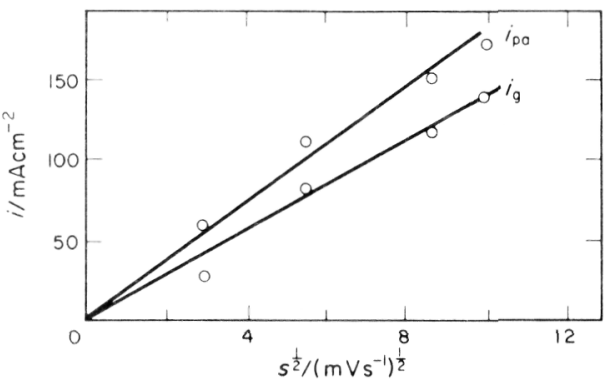

Fig. 8. Experimental relationship for AgI film growth between the anodic peak current $\left(i_{\mathrm{pa}}\right)$ and the post-peak current $\left(i_{\mathrm{g}}\right) v s s^{1 / 2}$ in $1 \mathrm{M} \mathrm{NaI}$ at $\omega=17 \mathrm{~Hz}$.

more dilute iodide concentrations, the anodic current after the anodic peak region, $i_{\mathrm{g}}$, now remains large and relatively constant with increasing potential rather than decreasing continuously even with increasing potential. Upon sweep reversal to the cathodic direction, the current can be seen in Fig. 7 to drop approximately linearly to zero as would be characteristic of film growth controlled by a field-dependent process[2], rather than exhibiting the gradual decline of current of Fig. 4.

When the potential is extended to about $0.75 \mathrm{~V}$ in $1 \mathrm{M} \mathrm{NaI}$ solutions, no anodic current attributable to the occurrence of reaction (3) is observed (Fig. 7). Instead, the current remains constant and independent of the potential until the direction of potential sweep is reversed. This may indicate that no free $\mathrm{Ag}$ is available for reaction (3) to occur and that the pores in the film are no longer carrying the current.

An SEM view of an AgI film formed in $1 \mathrm{M} \mathrm{NaI}$ solutions is given in Fig. 9 and a very granular type of film can be seen. The gaps or the pores which are seen in Fig. 9 are probably sealed further in towards the $\mathrm{Ag}$ base. The surface appears quite different from that in Fig. 6 for an AgI film formed in $0.1 \mathrm{M} \mathrm{NaI}$ solutions and may indicate that a different mechanism of film formation now exists, perhaps involving $\mathrm{AgI}$ dissolution and precipitation. This effect of dissolution can be seen particularly at low $s$ where the ratio of the anodic to the cathodic charge densities can be up to 2.5 .

A model of AgI film growth which would best fit the experimental observations in $1 \mathrm{M}$ iodide solutions is as follows. Initially, the rate of AgI film growth is controlled by the rate of ionic migration in the bulk of the solution. This is seen by the proximity of the

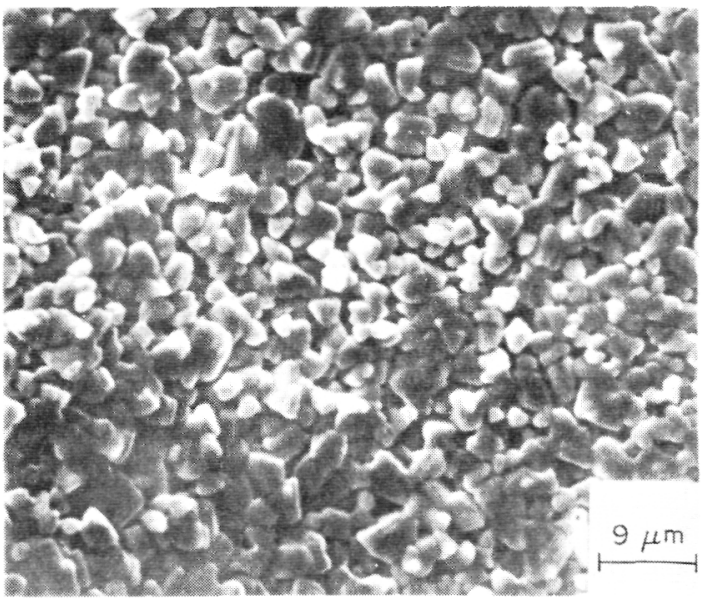

Fig. 9. SEM view of $\mathrm{AgI}$ film formed in $1 \mathrm{M} \mathrm{NaI}$ at $s$ $=50 \mathrm{mV} \mathrm{s}^{-1}, \omega=13 \mathrm{~Hz}$, when potential sweep terminated at $0.67 \mathrm{~V} /$ nhe (see Fig. 7).

observed value of the inverse of the leading slope of the anodic current peak to the calculated value of the solution resistance (4). Also, the observed linear relationship between $I_{\mathrm{p}}$ and $s^{1 / 2}$ (Fig. 8) is predicted for the formation of a porous film at a rate limited by the resistance of the bulk electrolyte and the electrolyte in the pores of the film[1]. However, it is important to note that at high $s$, no anodic peak is observed in $1 \mathrm{M}$ NaI solutions, and then $i_{\mathrm{p}}=i_{\mathrm{g}}$, which indicates that the peak seen at low $s$ may be due primarily to the dissolution of AgI.

After the current peak in Fig. 7, the current $\left(i_{\mathrm{g}}\right)$ remains constant with increasing potential but varies linearly with $s^{1 / 2}$. With sweep reversal, $i_{\mathrm{g}}$ drops rapidly with the decreasing potential, which is consistent with the low-field approximation for film growth limited by solid-state ionic transport across the film[2]. In the case of the low-field approximation, (5) (Ohm's law) applies[12]

where $\quad \begin{aligned} i_{\mathrm{g}} & =\kappa_{\mathrm{i}} \xi \\ \xi & =\frac{V}{l}\end{aligned}$

and where $\kappa_{\mathrm{i}}$ is the ionic conductivity of the $\mathrm{AgI}$ film, $\xi$ is the electric field across the film, $V$ is the voltage distributed across the film and $l$ is the film thickness.

If it is assumed that only film thickening is occurring after the anodic peak, then Faraday's law can be expressed as in (7)

$$
i_{\mathrm{g}}=\frac{z F \rho}{M} \frac{\mathrm{d} l}{\mathrm{~d} t},
$$

where $\rho$ is the film density $\left(5.7 \mathrm{gcm}^{-3}\right)$ and $M$ is the film molecular weight $\left(235 \mathrm{~g} \mathrm{~mole}^{-1}\right)$.

As

$$
\mathrm{d} V=s \mathrm{~d} t
$$

then

$$
i_{\mathrm{g}}=\frac{\left(\kappa_{\mathrm{i}} z F \rho\right)^{1 / 2}}{M} s^{1 / 2}
$$

From (9), $\kappa_{\mathrm{i}}$ for anodically formed AgI films can be obtained from the experimentally obtained $i_{\mathrm{g}} / \mathrm{s}^{1 / 2}$ plot (Fig. 8). From the slope, $\kappa_{\mathrm{i}}$ is found to be equal to 8.7 $\times 10^{-5} \mathrm{~S} \mathrm{~cm}^{-1}$. This is a reasonable value when 
compared to others in the literature, such as a conductivity of between $10^{-6}$ and $10^{-4} \mathrm{~S} \mathrm{~cm}^{-1}$ for $\gamma-\mathrm{AgI}$ [13] and between $10^{-5}$ and $10^{-4} \mathrm{~S} \mathrm{~cm}^{-1}$ for $\beta-\mathrm{AgI}[14]$.

Therefore, it appears that in $1 \mathrm{M}$ iodide solutions the AgI film is essentially a compact one so that current moves via a solid-state field dependent path and the low-field approximation is valid. In more dilute iodide solutions, the pore morphology seems to be maintained and hence current follows the pores and is then limited by ionic migration and diffusion in the electrolyte within the pores of the AgI films.

\section{SUMMARY}

A potentiodynamic study of the anodic formation of $\mathrm{AgI}$ films on an $\mathrm{Ag}$ electrode in aqueous iodide solutions was carried out in conjunction with SEM examinations of the morphology of the AgI films. In general, it was found that the electron transfer reaction between $\mathrm{Ag}$ and $\mathrm{I}^{-}$is fast so that physical processes limit the rate of $\mathrm{AgI}$ film formation.

In dilute iodide solutions, the rate limiting step to the film growth process is the diffusion of $\mathrm{I}^{-}$in solution to the $\mathrm{Ag}$ electrode surface. At higher $\mathrm{I}^{-}$ concentrations up to about $0.1 \mathrm{M}$, the rate of $\mathrm{AgI}$ film growth is initially limited by ionic migration in solution and a very porous AgI film develops. As the pores of the film lengthen, further film growth then becomes limited by the diffusion of $\mathrm{I}^{-}$in the pores of the film to the $\mathrm{Ag}$ substrate. SEM examinations have supported this mechanism of growth by revealing very porous and high area $\mathrm{AgI}$ film surfaces.

In $1 \mathrm{M} \mathrm{I}^{-}$solutions, the AgI film becomes quite soluble and it appears that a different mechanism of AgI film growth prevails. Now a granular but more compact AgI film is seen by SEM and the rate of film growth is now limited by the ionic migration of $\mathrm{Ag}^{+}$ under the influence of the field in the AgI film. On the basis of the low field model of film growth, the ionic conductivity of the AgI films has been determined to be $8.7 \times 10^{-5} \mathrm{~S} \mathrm{~cm}^{-1}$, which is in close agreement with previous determinations of the ionic conductivity of AgI.

Acknowledgements-V.I.B. gratefully acknowledges the receipt of a Commonwealth Scholarship from Canada to New Zealand from the New Zealand grants committee.

\section{REFERENCES}

1. V. I. Birss and G. A. Wright. Electrochim. Acta 27, 1429 (1982).

2. V. I. Birss and G. A. Wright, Electrochim. Acta 26, 1809 (1981).

3. V. I. Birss and G. A. Wright, ibid 27, 1 (1982).

4. M. Babai, T. Tshernikovskii and E. Gileadi, J. electrochem. Soc. 119, 1018 (1972)

5. L. Bircumshaw and A. Riddiford, Q. Rev. chem. Soc. 6, 157 (1952).

6. R. Parsons, Handbook of Electrochemical Constants. Butterworths, London (1959).

7. N.R.C. of America, International Critical Tables, (Edited by E. W. Washburn) Vol. 5. McGraw-Hill, New York (1929).

8. J. Newman, J. electrochem. Soc. 113, 501 (1966).

9. W. J. Mueller, Trans. Faraday Soc. 27, 737 (1931).

10. A. J. Calandra, N. R. de Tacconi, R. Pereiro and A. J. Arvia, Electrochim. Acta 19, 901 (1974).

11. J. Bjerrum, Stability Constants of Metal-Ion Complexes, Chem. Soc. London, Special Publication No. 17.

12. N. Cabrera and N. F. Mott, Rep. Prog. Phys. 12, 163 (1949).

13. T. Takahashi, K. Kuwabara and O. Yamamoto, $J$. electrochem. Soc. 116, 357 (1969).

14. G. Cochrane and N. Fletcher, Physics Chem. Solids 32, 2557 (1971). 